\title{
Notiz über die Galle von Isabellbären.
}

Von

\section{Dr. Leo v. Zumbusch.}

(Aus dem Laboratorium für angewandte medicinische Chemie in Wien.) (Der Redaction zugegangen am 22. Mai 1902.)

Anlässlich der Tödtung dreier Isabellbären, welche im Wiener Thiergarten gehalten worden waren, hatte ich durch das freundliche Entgegenkommen des ersten anatomischen Universitätsinstituts Gelegenheit, die Galle dieser Thiere im frischen Zustande $\mathrm{zu}$ sammeln und $\mathrm{zu}$ verarbeiten. Da die Resultate meiner Untersuchung eine vielleicht brauchbare Ergänzung zu den umfassenden Untersuchungen Hammarsten's über die Galle der Eisbären bilden, seien sie im Folgenden kurz zusammengefasst:

Der Isabellbär ist eine in Syrien heimische, dem gewöhnlichen braunen Bären nahestehende Art; die im Wiener Thiergarten befindlichen Exemplare waren jahrelang dort gehalten worden, sie wurden mit Pferdefleisch gefüttert (nach Brehm soll der Isabellbär in seiner Heimath vorwiegend Pflanzenfresser sein), die Thiere waren munter und anscheinend gesund.

Nachdem circa $10 \mathrm{~g}$ unzersetzten Cyankaliums pro Thier nicht den raschen Tod herbeigeführt hatten, wurden die Thiere durch Erdrosseln getödtet.

Erwähnt sei, dass sich aus einem bei der Section entnommenen Muskelstücke durch Destillation eine allerdings geringe Blausäuremenge gewinnen liess.

Die Gesammtmenge der aus den drei Thieren erhaltenen Galle betrug $125 \mathrm{ccm}$. Sie war eine tief olivgrüne, stark fadenziehende, schwach nach Moschus riechende Flüssigkeit, die beim Stehen ein reichliches, aus amorphen Krümeln bestehendes Sediment gab. Die Reaction der Galle war sehr schwach alkalisch, das specifische Gewicht war 1,027 $\mathrm{g}$ bei $16^{\circ} \mathrm{C}$.

Die gebräuchlichen Gallenfarbstoffreactionen waren in ausgezeichneter Weise zu beobachten, besonders die Huppert'sche 
Probe war schon mit einer winzigen Menge der Galle schön zu erhalten. Auf Zusatz von Ammoniak und Chlorzinklösung zeigte die verdünnte Galle eine deutliche Fluorescenz ins Grüne; Streifen konnten bei der spectroskopischen Untersuchung dieser Flüssigkeit keine gesehen werden, sondern nur eine Auslöschung der Enden. Der Trockenrückstand der Mischgalle bei $110^{\circ}$ bestimmt betrug $13,77 \% ; 5,1403 \mathrm{~g}$ Galle gaben $0,7082 \mathrm{~g}$ Trockenrückstand.

Nach dem vorsichtigen Veraschen des Trockenrückstandes blieben $0,0563 \mathrm{~g}=1,095 \%$ röthlich gefärbter Asche. Hiervon gingen $0,0435 \mathrm{~g}$, das ist 77,26\% der Asche mit Wasser in Lösung. Die wässerige Lösung war von alkalischer Reaction, sie enthielt reichlich Chlor, Phosphorsäure und Schwefelsäure; als Metalle konnten Natrium und Calcium sowie eine sehr geringe Menge Kalium nachgewiesen werden.

Der wasserunlösliche Theil der Asche löste sich unter reichlicher Kohlensäureentwickelung vollkommen in Salzsäure auf. In der Lösung war Phosphorsäure und eine Spur Schwefelsäure (welche wohl einer kleinen Menge der Auflösung im Wasser entgangenem Gyps entspricht), sowie Calcium und Eisen nachweisbar.

Die übrige Gallenmenge, etwa $110 \mathrm{ccm}$., wurde mit dem fünffachen Volumen $96 \%$ igen Alkohols versetzt; es schied sich alsbald ein sehr reichlicher, rothbrauner, flockiger Niederschlag $a b$, über dem eine klare, tief olivgrün gefärbte Flüssigkeitsschicht sich befand. Nach 24 Stunden wurde die weingeistige Lösung durch Absaugen von dem Niederschlag getrennt, derselbe mit concentrirtem Alkohol angerieben, nach 24 Stunden abermals abgesaugt und gut mit Weingeist nachgewaschen.

Der Niederschlag blieb trotz guten Auswaschens intensiv braunroth gefärbt und wog bei $105^{\circ}$ getrocknet 7,413 g. Er stellte getrocknet eine dunkelbraune, spröde, leicht zerreibliche Masse dar.

$1,1250 \mathrm{~g}$ des Niederschlages ergaben geglüht $0,0375 \mathrm{~g}$ oder $3,24 \%$ Asche, welche sich qualitativ nicht von der Gesammtasche unterschied.

0,5618 g zur Stickstoffbestimmung nach Kjeldahl verHoppe-Seyler's Zeitschrift f. physiol. Chemie. XXXV. 
wendet brauchten zur Neutralisation des gebildeten Ammoniaks $5,628 \mathrm{ccm}$. Normalschwefelsäure, was $0,0788 \mathrm{~g}$ oder $14,03 \%$ Stickstoff entspricht.

$0,5888 \mathrm{~g}$ brauchten $6,008 \mathrm{ccm}$. Normalschwefelsäure, was $0,0841 \mathrm{~g}$ oder $14,28 \%$ Stickstoff entspricht.

$0,7238 \mathrm{~g}$ mit Soda und Salpeter geschmolzen ergaben 0,0253 g Baryumsulfat, d. i. 0,0035 g oder 0,484\% Schwefel.

Der aus dem Mittel der beiden Bestimmungen sich ergebende Stickstoffgehalt von 14,155\% ist etwas höher als der, welcher bei den echten Mucinen gefunden wurde, ${ }^{1}$ ) jedoch bedeutend niederer als der von den mucinähnlichen Nucleoalbuminen, wie ein solches Paijkull²) aus Rindsgalle dargestellt hat; dieses enthielt 16,14\% Stickstoff; ein anderer Unterschied liegt im Schwefelgehalt, da von Paijkull 1,66\% Schwefel gefunden worden waren, wogegen unsere Substanz nicht ein halbes Procent Schwefel enthielt.

Der im Niederschlag enthaltene Farbstoff liess sich weder durch Wasser, verdünnte Säuren oder Sodalösung, noch durch Alkohol, Aether, Chloroform oder Benzol extrahiren, nur Dimethylanilin nahm eine braunrothe Färbung an.

Bei Untersuchung dieser Lösung mit dem Spectroskop war nur eine Auslöschung der Enden des Spectrums, besonders des Violetten, wahrzunehmen.

Der in Alkohol lösliche Theil der Galle mit dem Waschalkohol vereinigt wurde bei $50^{\circ}$ im Vacuum auf ein Fünftel des Volumens eingedampft und zu der etwa $200 \mathrm{ccm}$. messenden Flüssigkeit so lange Aether zugesetzt, bis neuerlicher Aetherzusatz keine Trübung mehr hervorbrachte; hierzu war ungefähr die vierfache Aethermenge erforderlich.

Nach 24 Stunden konnte der Aether klar von dem gelbbraunen, krystallinischen, fest am Glase haftenden Niederschlag abgegossen werden, worauf die ausgeschiedenen gallensauren, Salze wiederholt mit Aether nachgewaschen wurden.

1) Nach Hammarsten's Lehrbuch, S. 39: Schneckenmucin 13,65\%, Sehnenmucin 11,75\%, Submaxillarmucin 12,32\%.

2) L. Paijkull, Schleimsubstanz der Galle. Diese Zeitschrit, Bd. XII, S. 196 (1887). 
Das Gewicht der Plattner'schen Galle betrug $1,14 \mathrm{~g}$, der Rückstand der Aetheralkohollösung 2,2 g. Letztere wurde durch 3 Stunden mit alkoholischer Kalilauge gekocht, die gebildete Seife wurde nach dem Vertreiben des Alkohols in viel Wasser gelöst, hierauf die trübe Lösung mit Aether mehrmals ausgeschüttelt.

Nach dem Verdunsten des Aethers blieb ein grossentheils krystallinischer Rückstand, der aus warmem Aceton umkrystallisirt $0,06 \mathrm{~g}$ typischen, durch die charakteristischen Krystalltafeln und die Reactionen mit concentrirter Schwefelsäure im Mikroskop, sowie mit Schwefelsäure und Essigsäureanhydrid identificirten Cholestearins ergab.

In der Meinung, dass die neben dem Cholestearin vorhandene fettige, nicht krystallinische Masse aus Fettalkoholen bestände, habe ich sie mit Natronkalk vermischt, in einem Rohr auf $160^{\circ}$ erhitzt in der Absicht, eine Fettsäure erhalten und, isolirt, charakterisiren zu können. Diese Absicht gelang nicht, indem die Menge des erhaltenen Reactionsproduktes so gering war, dass nur dessen Schmelzpunkt, als bei etwa $60^{\circ}$ liegend, festgestellt werden konnte. Leider ergab auch die Prüfung auf Phosphor, resp. auf lecithinartige Körper, wegen zu geringer Menge des zur Verfügung stehenden Materials kein Resultat. Die mit Aether ausgeschüttelte wässerige Seifenlösung wurde mit verdünnter Schwefelsäure angesäuert und durch Ausschütteln mit Aether ein bei $35^{\circ}$ schmelzendes Fettsäuregemisch erhalten.

Um die Säuren der Oelsäurereihe zu isoliren, wurde das Gemisch mit Bleiglätte verseift, die Bleiseife mit Aether extrahirt. Es wurden hierbei 0,642 $\mathrm{g}$ ätherlösliche Bleiverbindungen erhalten, deren Bleigehalt dem des ölsauren Bleies annähernd entsprach.

$0,4315 \mathrm{~g}$ der Substanz gaben 0,1623 g Bleisulfat, während sich für ölsaures Blei $0,1700 \mathrm{~g}$ Bleisulfat berechnen. Die geringe Differenz dürfte wohl auf eine Verharzung der Oelsäure, nicht aber auf die Gegenwart anderer ungesättigter Fettsäuren in der Galle selbst zu beziehen sein.

Der in Aether nicht lösliche Antheil der Bleiseifen gab 
nach seiner Zerlegung $0,20 \mathrm{~g}$ eines bei $55^{\circ}$ schmelzenden Fettsäuregemisches.

Durch Auflösen derselben in heissem Ammoniakwasser und Erkaltenlassen wurden $0,0410 \mathrm{~g}$ einer Säure, die in feinsten weissen Schüppchen ausfiel, erhalten, dieselbe schmolz bei $63^{\circ}$ und erstarrte bei $61,5^{\circ}$.

Sie wurde in Alkohol gelöst und mit 1/100-Normalkalilauge titrirt; verbraucht wurden $15,0 \mathrm{ccm} .(1 \mathrm{ccm} .=1,059 \mathrm{ccm}$. 1/100-Normal), verwendet waren $0,039 \mathrm{~g}$ der Substanz; daher beträgt das Molekulargewicht der Säure 245.

Beide Bestimmungen geben also der Palmitinsäure ziemlich entsprechende Werthe (Schmelzpunkt 620, Molekulargewicht 256).

Im Wasser, das nach Ausschütteln der Fettsäuren zurückblieb, konnte nach dem Eindampfen Glycerin durch die Akroleinprobe und den süssen Geschmack nachgewiesen werden. Beim Wiederauflösen der Plattner'schen Gallensäuren mit Alkohol blieb ein in Alkohol unlöslicher Rückstand. Zum Theil bestand derselbe aus Chlornatrium und anderen in Wasser löslichen anorganischen Salzen, zum Theil aber auch aus einem in Wasser nicht so schnell wie die Salze, in Alkohol gar nicht löslichen organischen Körper.

Derselbe bildet eingetrocknet feine bräunliche Lamellen, verbrennt am Platinblech ohne Rückstand und mit schwachem, an verbranntes Horn erinnerndem Geruch. Die Menge des Körpers war leider zu gering, um eine Elementaranalyse durchzuführen; er erwies sich als frei von Schwefel und Phosphor, gab nicht die Pettenkofer'sche Gallensäurereaction, auch keine Biuretreaction mit Kalilauge und Kupfervitriol. Beim Versuche, nachzuweisen, welcher Art die bräunliche Färbung sei, konnte nur constatirt werden, dass sie weder von Bilirubin noch von Urobilin herrühre.

Ich versuchte nun, durch fractionirte Fällung eine Trennung der einzelnen in der Plattner'schen Galle enthaltenen Gallensäuren durchzuführen. Es gelang dies aber weder durch Zusatz von Aether in kleinen Antheilen zur alkoholischen Lösung, noch durch vorsichtiges Aussalzen der möglichst 
gesättigten wässerigen Lösung mittelst Ammonsulfat; auch der letzte Versuch, die fractionirte Fällung durch Bleiessig, gab keine wohlcharakterisirten Fractionen. Daher wurden die Fractionen wieder vereinigt und sogleich dem Nachweis ihrer Spaltungsprodukte zugeführt, indem sie 24 Stunden mit Barythydrat auf dem Sandbad zum Sieden erhitzt, die Masse wiederholt mit Wasser extrahirt und die Cholalsäure durch Zusatz der gleichen Menge rauchender Salzsäure zum eingeengten Extract bei niederer Temperatur als flockiger Niederschlag gefällt.

Dieselbe wurde durch Lösen in Alkohol und Kochen mit Thierkohle entfärbt, dann durch wiederholtes Lösen in Kalilauge und Fällen mit rauchender Salzsäure gereinigt, endlich chlorfrei gewaschen und im Vacuum über Schwefelsäure durch einen Monat getrocknet.

Das Präparat wog 0,30 g, war schneeweiss, locker, amorph, in Wasser so gut wie unlöslich, dagegen leicht löslich in Alkohol und Alkalien, frei von Asche; dasselbe gab die Pettenkofer'sche Reaction, jedoch mit einem etwas dunkleren, violetten Farbenton. Beim Erhitzen auf ca. 80 schmolz es unter schwarzer Verfärbung.

Die Verbrennung nach Liebig, mit Kupferoxyd ausgeführt, ergab:

I. $0,1140 \mathrm{~g}$ Substanz ergaben $0,1050 \mathrm{~g} \mathrm{H}_{8} \mathrm{O}=0,0116 \mathrm{~g} \mathrm{H}=10,18^{\circ} \%$ $0,3059 \mathrm{~g} \mathrm{CO}_{\mathbf{2}}=0,0834 \mathrm{~g} \mathrm{C}=73,20 \%$. II. $0,1050 \mathrm{~g}$ Substanz ergaben $0,0942 \mathrm{~g} \mathrm{H}_{8} \mathrm{O}=0,0105 \mathrm{~g} \mathrm{H}=10,00 \%$ $0,2829 \mathrm{~g} \mathrm{CO}_{\mathbf{g}}=0,0771 \mathrm{~g} \mathrm{C}=73,43 \%$. Im Mittel also: $10,09 \% \mathrm{H}, 73,315 \% \mathrm{C}$.

Diese Zusammensetzung kommt am nächsten der von Lassar-Cohn ${ }^{1}$ ) beschriebenen Choleinsäure, die bei der Formel $\mathrm{C}_{24} \mathrm{H}_{40} \mathrm{O}_{4} 73,47 \%$ Kohlenstoff und 10,20\% Wasserstoff enthält. Paarlinge der Gallensäuren in reiner Form darzustellen, gelang nicht. Glycocoll konnte überhaupt nicht nachgewiesen werden, bezüglich des Taurins sei nur erwähnt, dass der Rückstand im Ganzen 0,205 g wog und 0,023 g Schwefel in organischer Bindung enthielt.

Wien, Mai 1902.

1) Diese Zeitschrift, Bd. XVII, S. 606. 